\title{
Anthropology of virtual worlds: history, current debates and future possibilities
}

\author{
Lea-Maria Kerschbaumer \\ Department of Social and Cultural Anthropology, University of Vienna \\ lea.kerschbaumer@gmx.at
}

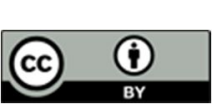

Received: $10 / 11 / 16$

Accepted: 20/11/16

Published: 01/12/16

\section{Resumen}

La importancia de la investigación de los mundos virtuales ha ido incrementando y poco a poco se ha convertido en una parte importante de la antropología digital en los últimos años. Ofrece así posibilidades prometedoras para la ciencia social, como la realización de experimentos en los mundos virtuales. Sin embargo, el campo está lejos de estar unificado en muchos aspectos, y el debate sobre las definiciones, los usos y los términos importantes no está aún concluído. Este artículo ofrece una introducción a los mundos virtuales, la participación antropológica en este tema y los actuales discursos antropológicos, terminando con el debate de las perspectivas de la investigación de percepciones y las prácticas de violencia dentro de los mundos virtuales.

Palabras clave: mundos virtuales; Antropología digital; mmorpg; autenticidad; violencia; dolor.

\section{Abstract}

The research of virtual worlds has become an increasingly important part of digital anthropology in recent years and offers promising possibilities for social science, such as conducting experiments in virtual worlds. However, the field is far from being unified on a lot of topics and the discussion about definitions, uses and important terms is not yet finished. This article provides an introduction to virtual worlds, anthropological involvement with that topic and current anthropological discourses, finishing with a discussion of the prospects of researching perceptions and practices of violence within virtual worlds.

Keywords: virtual worlds; digital anthropology; mmorpg; authenticity; violence; griefing

\section{Index}
1. Introduction
4. Conclusion

2. Virtual Worlds

5. References

3. Violence 


\section{Introduction.}

Virtual worlds have always fascinated me. As a teenager I would spend many hours in them, chatting with friends, completing tasks and exploring their boundaries. When I first learned about anthropological research within virtual worlds, I was thrilled. Not only could I use my interest in virtual worlds for a productive purpose, this field also promised to open a broad range of new opportunities for anthropological research. Especially the possibility of using virtual worlds to research societies on a level that was never before feasible for social science fascinated me enormously. With my MA thesis I hope to take a step into this direction. I want to explore what "violence" means for the users of a virtual world where fighting and conflicts form the foundation of their game experience and which role violence plays in the larger society of the virtual world. This text serves to provide the theoretical background to my MA research project and is meant to introduce the reader to the matter of anthropological research in virtual worlds.

This essay will include an introduction to virtual worlds and a discussion of their characteristics and I will also give a general introduction into anthropological research within virtual worlds. I will locate the field within the larger framework of digital anthropology, as well as give an overview of research within virtual worlds. I will further tackle some central discussions within this field, such as the question of the opposite to "virtual", issues of ethics and what anthropology can gain from researching virtual worlds. I will then briefly insert my own research interests and the theoretical background used for this project.

\section{Virtual Worlds.}

\section{Locating virtual worlds in the field of digital anthropology}

Digital anthropology is dealing with a broad range of topics and fields, ranging from the use of digital images for remembering, to utilizing Facebook to create national identities and studying social behaviour in virtual worlds (Daniel Miller \& Horst, 2012). Due to the sheer size and the many opportunities of this field, there are various definitions. Some use more restrictive definitions of digital anthropology to avoid watering down its meaning, while others seek to maintain the variety of possibilities an open definition offers to digital anthropology as a field.

According to Budka and Kremser (2004) the first approach to digital anthropology was made in Escobar's article "Welcome to Cyberia" in 1994. Escobar created the term "cyber culture" to analyse the transformation of the structure of modern society made by computer aided information technology and biological technology. He paid special attention to the research of the social constructions that form the basis for those new technologies. Budka and Kremser use his approach to name three areas of digital anthropology. First, research should be done where information and communication technologies, shortly ICTs, are produced and used. This includes computer companies, laboratories, work places, design centres, schools, homes and so on. Second, social networks formed or kept via ICTs should be part of the research, as well as virtual communities and their language and social structure. The third approach deals with political and economic aspects of ICTs. 
While Budka and Kremser follow a very broad definition of digital anthropology that covers everything from the production of ICTS to virtual communities, Boellstorff $(2008,2012)$ distinguishes the research of virtual worlds from general digital anthropology by calling this subfield cyber anthropology. Even though those terms are often treated as synonyms, he argues for separating cyber anthropology from digital anthropology, with the argument that nowadays internet-mediated communication and content can be found in almost every field of anthropology. He argues towards seeing digital anthropology as a technique for researching social interaction via digital technology, while cyber anthropology should not deal with the usage of internet or ICTs, but rather with the cultures that form in virtual worlds.

I agree with this suggestion, as the anthropological engagement with virtual worlds is very different from, for instance, the occupation with smart phones. Using the term cyber anthropology for this specific subfield makes it easier to clarify what one is talking about and would also simplify the literature research.

\section{Terms and Definitions}

In order to define "virtual world", one first has to think about the term "virtual". The Oxford Dictionary gives "almost or nearly as described" as definition for "virtual". In the case of virtual worlds this means that the virtual world is "almost a world". This could easily be misunderstood as virtual meaning not real, but, as every user of virtual worlds could confirm, virtual worlds are very much real, they are just not the same as the non-virtual world.

\section{Virtual, real and actual}

Boellstorff uses a very simple argument to dismiss the use of "real" as the opposite of virtual: "Assuming that virtual worlds are not real undermines our scholarly work on them: why bother studying virtual worlds if they are not real?" (Boellstorff 2015: 2). While users often use "real life" or "real world" when they talk about things outside of their virtual world, only very few would agree that the virtual world is not real in any sense, since they spend real hours, often real money and form real relationships with others while interacting with the virtual environment.

Boellstorff therefore identifies "actual" as the opposite to "virtual" and argues that "[...]'virtual" connotes approaching the actual without arriving there"(Boellstorff 2008: 19). A virtual world is therefore trying to emulate places, societies, objects and creatures as precisely as possible, but it does not cross the line to becoming physical reality. In a later publication, Boellstorff admits to using "virtual", "digital" and "online" as rough equivalents and does not mention the term "actual" as the opposite at all. He continues to insist that placing "real" on one side of the spectrum and "virtual" on the other is misrepresenting virtual worlds as valid places of human interaction and laments that the term "real" is hardly ever defined in discussions about virtual worlds. However, he does not offer a satisfactory alternative to using the phrase "real world" (Boellstorff 2015).

Nardi on the other hand uses the term "real" as the opposite to virtual and argues that "actual" carries the same semantic fault as "real". Other terms such as "offline" or "physical" are also inadequate as they suggest that online and non- 
physical are only inherent to virtual worlds. She therefore sticks with the word that most people use when they talk about their life outside of the virtual world:

"'Real world' is a folk term in gamer (and other) discourse, and its consistent use in an established lexicon recommends it in the absence of a better academic term. When I questioned gamers about why they spoke of 'the real world,' they replied, 'Well, we have to call it something.'"(Nardi 2015: 20).

Nardi further suggests that language is still catching up with the new reality of virtual worlds and that, even though currently no appropriate term to describe the opposite of virtual exists, this might change in the future.

Personally, I agree with both Boellstorff's and Nardi's points. While I strongly disagree with treating virtual worlds as "unreal", Nardi is right by pointing out that "actual" carries the exact same connotations as "real". Her decision to use "real world" as the opposite to "virtual world" stems from the lack of better alternatives and the wide spread use of this term within the community of virtual worlds' inhabitants. While I would appreciate the introduction of a more suitable word to describe the non-virtual, as long as our language has not developed one, I can agree to using the problematic, but common "real".

\section{Definitions and characteristics of "virtual world"}

As varied and heated the debates about the terms "virtual" and "real" are, definitions from different scholars for "virtual world" are strikingly similar.

Klastrup and Tosca (Klastrup \& Tosca 2004: 413) call virtual worlds "cyberworlds" and define them as such:

"We understand cyberworlds to be computer mediated, networked and spatially navigable multi-user environments. They contain the possibility to interact in real time with other users and to actively interact with and influence the world itself. They can be game worlds or entertainments world or social worlds, but most cyberworlds provide all three opportunities (gaming, being entertained, socialising) in some form".

For something to be a virtual world Boellstorff (2008) argues that it must be a place inhabited by real people realized by online technologies. Castronova (2005b: 22) states that a virtual world is a

"[...] synthetic world", by which I mean any computer-generated physical space, represented graphically in three dimensions, that can be experienced by many people at once."

All definitions agree that to call a computer mediated environment a virtual world, three basic conditions must be given: First, it has to be realized by computer and information technologies, second, it has to be inhabited and experienced by many people at the same time and third, it has to be recognized as a place, although it does not matter if this place is experienced graphically or textually.

The virtual world as a place is a concept that sets virtual worlds apart from, for instance, online forums or social media platforms. Being able to experience a virtual world in a spatial sense can be broken down into spatial orientation, connectedness and the possibility of exploration. Most virtual worlds nowadays 
are graphic virtual worlds and are in 3D, so often virtual worlds are misunderstood as only existing in a graphic 3D sense. According to Pearce (2009), virtual worlds can easily be textual or only existing in 2D, as long as all participants share a similar idea of how the place looks and how to navigate in it.

Connectedness describes virtual world's inherent trait of consisting of connected areas, zones or rooms. Virtual worlds, whether graphic or textual ones, are mappable. This mappability in turn encourages users to explore the world and move around. Pretty much every area in a virtual world is made to be explored; restrictions or forbidden zones are connected to the inherent rules and stories of the game. Often areas get unlocked once the user reaches a certain level or unlocks certain achievements. Other zones might be permanently restricted for certain player characters, due to wrong group membership or character class. In addition, virtual worlds are coherent in themselves. This means that in addition to all the aforementioned traits, the different aspects of the virtual world, like aesthetics, rules, background story, objects and so forth, match. For example, if a virtual world is called "Age of Camelot" and revolves around the legend of King Arthur, users might find it weird if they can use space ships to move around. If, on the other hand, they use horses, it matches their expectations and the virtual world appears coherent.

Another central characteristic of virtual worlds, the necessity of being inhabited by many people at the same time, can be further structured into malleability, social relations and the participation of every user. In contrast to other media like books or movies, the user is an actual part of the virtual world and interacts with it and, within the borders the developers set, also change it. Every user has a role within the virtual world and even if someone decides not to form relationships with other people online and tries to stay away from social contact, his or her actions are still going to be noticed by others acting in the same environment. This sociality is another central attribute of virtual worlds. They are inhabited by thousands of people sitting in front of their computers, generating the necessary social layer.

All those people interacting with and influencing their environment would of course become meaningless if the virtual world would disappear when the user logs out. Permanence is therefore an essential part of virtual world. It ensures that almost everything users created or influenced persists even if everyone logs out and the virtual world is left with no inhabitants. Only through this feature it becomes possible and worthwhile to pursue goals, solve long term tasks and build social networks.

Another essential feature virtual worlds must possess for users to develop their social networks is the recognisability of the users. People have to, in one way or another, have a consistent identity that makes them recognisable to others. Virtual worlds ensure this by making certain aspects of the embodiment of the user in the virtual world, also known as the avatar, unchangeable and unique. Commonly this is the name users select during the creation of an avatar, and often the chosen player class cannot be changed as well. Even if a person can change their appearance in the game, others can identify them by their name (Boellstorff, Nardi, Pearce, \& Taylor, 2012; Pearce \& Artemesia, 2009).The issue of being able to change one's personification in virtual worlds has fuelled one of the main arguments against the usefulness of online research. 


\section{The question of authenticity}

In the field of study of internet culture, and especially for the study of virtual worlds, one critique or question has been especially prominent: How is the ethnographer to know if the interlocutors' statements are true? A popular phrase is "on the internet, you can be anything", and many critics fear that this statement is so true that it endangers the usefulness of gathered data. While statements about online activities can be easily examined for their truthfulness, the veracity of information about the interlocutors' offline identities is harder to confirm, and sometimes it is outright impossible. This critique is often used to undermine the usefulness of research of online social relationships, as it assumes that the authenticity of people's identity performances online is insufficient and the research is therefore worthless. The following chapter is structured in a theoretical examination and deconstruction of the presumptions leading to that critique, followed by more practical reflexions.

The critique of an ethnographer's ability to confirm the truthfulness of interlocutors' accounts about their offline self presumes certain ideas about identity and authenticity. It postulates the correspondence between the online identity witnessed by the ethnographer and the performances of identity in other online or offline places. Identity in this case is defined as a singular thing, liked to a physical body with a similarly singular identity (Hine, 2000). This notion is problematic, as anthropology has long since shown that humans do not possess a single, rigid identity, but several that can change depending on the social role a person currently acts out. Identity can be understood as a flexible, fluid construct of different aspects of a person's life that is not performed the same way in every social context (Turkle, 1999).

Critiques against the usefulness of anthropological research in virtual worlds often argue that players use them as a means for escaping reality and that their behaviour online therefore cannot be taken seriously. Boellstorff (2008) disagrees with this argument, stating that far not every user of virtual worlds tries to escape reality by behaving radically different than they normally would. And even if this was the case, people offline also engage in behaviour that lets them escape reality, like dressing up as someone else or reading books. Turkle (1999) similarly argues that trying out new identities or ways of presenting oneself is not something new. Before the internet, college was said to be the place to experiment with identities. However, we must let go of the idea that identity is singular and accept that identity consists of different parts of the self. Just because some man plays as a woman online does not mean that he is deceiving anyone. He might just live out a part of himself that he does not or cannot live out offline.

Hine (2000) suggests to treat authenticity not as an a priori problem, but rather research how our informants deal with the matter and how the field regards questions of authenticity. The importance of lining up one's online identity with defining aspects of one's offline identity varies strongly from online platform to online platform (Turkle, 1999). For some, like online dating sites, the correlation between offline ad online identity is incredibly important, for instance when we think about gender or place of residence. In other contexts, those aspects play a subordinated role, for example when discussing music in a Facebook group. 
Taylor claims that in virtual worlds in-game social relations and identities are the defining features of relationships between users. Offline relations and identities still exist and can play a role, but the avatar is the basis for a player's identity in the game. An interlocutor of Taylor reflects on this situation, thinking about how other people refer to her as her avatar's name and how they only know things about her that are based on the interactions she had with them in-game. "I don't know really how old they are, what they do. It's all based on the avatar thing." (Taylor, 2006: 96). Still, her relations with them are valid, because real world identities do not matter as much as the actions online.

Verifying the truth of interlocutors' claims can be difficult or outright impossible offline, as well as online (Boellstorff et al., 2012). Due to anthropology's focus on cultural meanings and practices and the possibility to fill in knowledge gaps with participant observation and interviews with other informants, it is also not typically necessary. Carter (Carter, 2005) therefore proposes to view data gained from online interlocutors as authentic, unless the opposite is proven. Meeting with the interlocutor face-to-face is sometimes seen as the solution to this dilemma. However, while face to face interaction in some cases might be valuable to get a holistic impression of the field, for instance when online groups meet offline for a convention or a guild meeting, in other cases it might place the ethnographer in an asymmetric position and might threaten the experiential authenticity that comes from aiming to understand the world the way it is for informants (Hine, 2000).

While identity issues can be tricky in most online contexts, virtual worlds take it even further. Most offer the user the possibility to create more than one avatar and it is indeed a common practice to switch between characters. There are multiple reasons for users to do so. For some, it offers a possibility to get away from the social responsibilities attached to their main avatar and play alone for some time (Taylor, 2006), while others might use it to engage in behaviour they do not want associated with their primary game character. The most common reason, however, is for users to try out other ways of playing the game, for instance by being a healer instead of a warrior. Other users generally cannot know whether two avatars are being controlled by the same person, if this person does not share this information. This can make social relations online complicated, so that in many virtual worlds it is bon ton to readily share information one's multiple avatars (Boellstorff et al., 2012; Pearce \& Artemesia, 2009; Taylor, 2006). Some people even try to make their avatar's names similar so others can easily guess the connection between them. For example, one of my interlocutors during my fieldwork for my BA thesis named all his avatars after soft drink brands. The handbook for research in virtual worlds (Boellstorff et al., 2012) suggests that the easiest way to deal with this is to follow the field's lead. If multiple avatars are treated as if they are the same person, the anthropologist should do the same.

\section{The problem with informed consent}

While anthropologists might struggle to understand their interlocutor's identities, there is also the problem of making one's own identity as a researcher known to people in the field. Since the researcher's bodily representation in the virtual 
world does indeed look like every other person's, and in the flow of the game it might be impracticable to announce to every random player one meets that one is doing research, the issue of informed consent is a thorny one. Tackling this issue is strongly dependant on the virtual world and its functions. In some, it might be possible to have a self-description window somehow attached to the avatar that every other player can access. Other virtual worlds might allow to create a profile page with links to external websites. In those cases, introducing oneself as a researcher is relatively easy. Boellstorff, in his research in Second Life, took those opportunities and made his research interest known in his avatar's selfdescription. He also used the game's option to buy land and build a virtual house, which he turned into a publicly accessible headquarters for his research. However, many virtual worlds, especially those that belong to the role play spectrum, do not implement those features, so researchers in those worlds have to make their research interest known in a different way. Often they are joining player groups like "guilds", where most social interactions take place. When applying to those groups, they can inform the guild leaders, and in succession the guild members, of their intentions (Nardi, 2010; Taylor, 2006). But not every player group in virtual worlds is as closely guarded as the guild, most are temporary, random or so large that single people do not stand out. Some places in the virtual world, such as central cities, might even resemble busy, public areas offline, such as train stations. Asking every person for consent before including the observations made in this public space is both futile and impossible. Boellstorff et al make it the ethnographer's responsibility to recognize when they are entering a private space or conversation and act accordingly.

Other than in an offline setting, where inappropriate clothing, behaviour or an absent function can give the outsider away, in a virtual world the researcher normally does not stand out from the crowd. Therefore, the line to unintentional covert research is thin (Nardi, 2010). Introducing oneself whenever entering a new group setting can be inconvenient or impossible, especially since it is not common behaviour, and often the pace of the game does not allow for a long introduction. A possible way out of this dilemma could be to choose a user name that reveals the anthropologist's identity, like "anthropologist_doing_research" or "researcher_at_work". To my knowledge, this approach has not been tried before, so it is not clear whether it would induce questions from other players and encourage discussion and awareness about the anthropologist's presence, or if it would be treated like the rest of uncommon and weird user names and just be ignored (Boellstorff et al., 2012).

\section{History of virtual worlds and anthropological involvement}

This chapter will give a short introduction into the development of virtual worlds and introduce several ground-breaking virtual worlds. Furthermore, I will give a short summary about the history of anthropological research within virtual worlds.

\section{Evolution of virtual worlds}

Books play a surprisingly big role in this story, such as fantasy classics like J.R.R. Tolkien's works, which were often used as inspiration for virtual worlds, or Gibson's "Neuromancer", which coined the term "cyberspace" (Boellstorff et al., 2012). 
Table top and pen-and-paper games, like "Dungeons and Dragons", were heavily inspired by fantasy literature. Those games, in which players create game characters and develop and level them under the instructions of a "game master" over the course of many hours, are often said to be the direct predecessors of virtual worlds (Taylor, 2006).

Those pen-and-paper games influenced Bartle and Trobshaw while developing the first public virtual world in 1979. It was called MUD1 (Multi User Dungeon) and was a textual virtual world that fell into the fantasy genre. Users got a description of the world around them and could move around, fight monsters, solve puzzles, talk to other players and visit pubs by typing commands like "look" or "go". Another early important virtual world was LambaMOO that was released in 1999. The revolutionary aspect with LambdaMOO was that the entire textbased world was created and modified by users. By taking into account other player's creations and exactly describing one's project, it was possible to create and integrate gardens, houses and other objects into the virtual world. In 1986, Habitat, the first graphic virtual world, was released. The most interesting development was the creation of "avatars", the personification of the player in the virtual world. This term was borrowed from Sanskrit and originally means the embodiment of a god on earth. In the context of virtual worlds, the avatar is the embodiment of a user's character. In text-based virtual worlds, a graphic depiction of the player was neither possible nor necessary, but with a visual virtual world, it finally became possible to actually see oneself and other users within the virtual world (Boellstorff et al., 2012; Taylor, 2006).

Most of the virtual worlds developed from the late 90ies until now use a game concept where the player creates and levels an avatar by battling monsters or other players and completes various tasks. Roleplaying is also often incorporated. Many of those virtual worlds are situated within the fantasy genre, but science fiction or other genres have also been popular. Those games, for the first time in the history of virtual worlds, managed to draw a massive number of users. The importance of the roleplaying aspect and the high number of users can also be seen in the umbrella term of those kinds of virtual worlds: Massive Multi Online Role Playing Games, or MMORPG. The most popular of those games is "World of Warcraft", with eleven million paying users during its heyday. Even though the number has shrunk since, it still holds the first place when it comes to player numbers.

In the early 2000s, another type of virtual world emerged. Those resembled the aforementioned LambdaMOO and gave the users bigger freedom. Often there was no predetermined goal for the user to reach, no levels to climb, no story to play and little design of the world from the developer's side. The users developed and designed their own objects and buildings and shaped the world according to their imagination and needs. Social relationships and self-fulfilment were at the core of those virtual worlds. The 2003 launched virtual world "Second Life" is the most popular of this branch of virtual worlds with several million users (Boellstorff et al., 2012).

At the moment, MMORPGs continue to be the most popular virtual worlds, but with the growing number of users and available worlds, developers dare to get more creative. Some step away from the beaten track, such as the developers of 
"Ever, Jane". This virtual world evolves around Jane Austen's books and the romanticization of regency era England. Players do not combat, but rather use smiles, conversation and rumours to compete (everjane.com). Another upcoming MMORPG, "Chronicles of Elyria", introduces aging and dying, so players' avatars will eventually cease to exist (chroniclesofelyria.com). Those developments promise to provide thrilling research opportunities for social scientists for years to come.

\section{History of anthropological involvement with virtual worlds}

The involvement of social sciences with virtual worlds can be dated back to 1992, when Rosenberg published the findings of his participant observation in the virtual world "WolfMOO" under the title "Virtual Reality" (Bartle, 2004).

Hine is one of the most influential, early anthropologists to work with virtual worlds. Her book "Virtual Ethnography" (2000) perfectly outlines the dominant discourse about the internet of the late 1990ies. By describing the reactions to a court case that caused great furore online, she shows how happenings in the physical world and on the internet become blurred and argues for seeing the internet as culture as well as a cultural artefact. In addition, Hine also produced methodological reflections for online ethnography. Her ideas about the authenticity of online relationships have been used widely.

Boellstorff's ethnography "Coming of Age in Second Life", published in 2008, has become a classic of digital anthropology. His book is both a traditional ethnography, as it aims to cover as much as possible about the culture of "Second Life", and a plea for using traditional anthropological methods such as long term participant observation in a new digital setting. Other than many of his colleagues, Boellstorff decided not to meet his interlocutors offline and conducted all his research within the virtual world.

Taylor's "Play Between Worlds" (2006) is mainly a detailed ethnography about the MMORPG "Everquest", but also discusses different types of players, gender and social networks within virtual worlds. Taylor sees the constant crossing of the boundary between online and offline as the key feature of the internet and therefore did her fieldwork not only online, but also offline.

Nardi's work with the MMORPG "World of Warcraft" is of special interest to me, as I also pan to work with this virtual world. In 2010 she published her ethnography called "My Life as a Night Elf Priest", in which she writes down the insights of her years of fieldwork, focusing on the influence of the virtual environment on the players' behaviour and, by concentrating on Chinese players, on the cultural aspects of gaming. In other publications, she deals for instance with users with disabilities or with the question of how customs of a virtual world are learned.

Boellstorff, Nardi, Pearce and Taylor joined forces and, drawing from their experiences with fieldwork in virtual worlds, published "Ethnography and Virtual Worlds", the first handbook of method for ethnography in virtual worlds in 2012. They provide, among other topics, tips for successful interviews online, instructions on how to gather good screenshots and chat logs and suggestions regarding ethical questions that might arise while in the field. 
Castronova, although an economist instead of an anthropologist, is one of the most cited authors about virtual worlds. With his book "Synthetic Worlds" (2005b), he delivered an ethnography about the MMORPG "EverQuest" and dealt with several theoretical issues of research in virtual worlds. In other publications (Castronova \& Falk, 2009; Castronova, 2005a), he argues for social science to use virtual worlds as a space for experiments.

\section{On the value of research in virtual worlds - ethnography and experiments}

In this part I will argue why anthropology should get involved with virtual worlds and explain the value of researching something that is mainly an entertainment system for its users. I will further mention what possible use social science in general and anthropology in particular could get from this research. Simply because virtual worlds exist and humans form relationship within them, virtual worlds are a valid field for research. Anthropology aims to explore human interaction in all kinds of environments, and virtual worlds are one of them.

Scientific engagement with virtual worlds can be distinguished into two general approaches. The first one tries to find and use parallels between online and offline behaviour in order to gain further knowledge about the real world. The second approach is not so much interested in the similarities between online and offline, but rather concentrates on understanding phenomena in virtual worlds. Boellstorff and his colleagues are advocates of the second approach and aim to explore and describe the specific types of society, culture, communication and behaviour that form within virtual worlds. If comparisons can be drawn to other social spheres, this is convenient, but it is not the prime focus (Boellstorff et al., 2012).

The first approach argues for using virtual worlds to gain further insights in human social behaviour in the real world. Castronova suggests that using virtual worlds to carry out large scale experiments would be a major game changer for social science. In his 2001 research on market places in the virtual world "Everquest", he discovered that markets online behave according to the same economic basic principles like supply and demand that markets offline are subject to. He claims that using virtual worlds to execute controlled social experiments would lead to social scientists being able to study large scale social entities directly for the first time.

"Given this level of control [of virtual worlds], an easy and yet breathtakingly powerful research strategy almost immediately leaps to mind: build several synthetic worlds in exactly the same way, except for some difference in a variable of interest. Put hooks in the data stream so that relevant metrics within the container societies can be observed. Attract people into the worlds, sit back, and watch what happens. With controlled construction of synthetic worlds, what we have in effect is a laboratory for large-scale social science research." (Edward Castronova, 2005a: 17)

Other researchers like Bainbridge (2007) or Williams (2010) agree on the enormous potential of virtual worlds for large experiments, yet argue that a direct translation of online behaviour to offline contexts might not be possible and that first researchers must find out how to manage this translation and learn where it is not feasible. 
Nardi heavily criticizes the enthusiasm for experiments in virtual worlds and fears that a growing concentration on big data will lead to disdaining and ignoring the "painstaking work of ethnography" (Nardi, 2015: 18) and threaten anthropology as a subject.

While I agree that the new research possibilities might change the field of anthropology and add new methods, I do not believe that participant observation as the central method will lose its importance. I rather think that the combination and mutual influence of "being in the field", experiments and observation will lead to a bright future of social anthropology.

\section{Violence.}

\section{The social function of violence}

While social anthropology has been dealing in various ways with different forms of violence, the concept I found most useful for my research was Gluckman's approach states that violence within a society is, against first impressions, most often not antisocial, but rather a social and implemented aspect of society. He argues that conflict within and between small social units promotes the solidarity of larger social units and that expressions of hostility in rituals serve as symbolic reaffirmations of the order of society. In "the peace in the feud" (Gluckman, 1955) he demonstrates how conflicts between two tribes lead to the momentarily cease of conflicts within the tribes to join forces against the common enemy. He also shows that there are different rules of behaviour that is deemed acceptable when it comes to conflict, depending on whether the opponent comes from the same tribe, comes from another tribe, or comes from outside of the tribe system.

In many MMORPGs, there are so-called factions, predetermined groups that are in constant conflict with each other. Users must choose the faction they want to belong to when starting the game, and are unable to change it for the duration of their stay in the virtual world. Those factions could be compared to Gluckman's "vengeance group", a group of people one is generally associated with through descendent that is supposed to band together against an enemy from the outside. Through attacking rival groups and thus re-establishing the animosity the developers wanted to harbour, the players reaffirm the structure of the virtual world's society:

"The paradox of violence in online worlds is that while it generates moral outrage, it also encourages players to band together into tightly knit groups of trusted comrades. These groups - tribes, clans, families, or guilds - are what [...] online culture in general is really all about." (Foo \& Koivisto, 2004: 245)

\section{Violence in virtual worlds}

Combat is a major and expected factor in MMORPGs and fighting against monsters or other users is a large part of the game experience. However, as Nardi (2010) explains for "World of Warcraft", most of those actions are not perceived as particularly violent. Most users see it as a way to keep score and 
exert their abilities, competing against each other and the game world. In World of Warcraft, there are no blood splatters or gruesome details.

In fact, it is an overwhelming amount of activities in virtual worlds that involve fighting or killing in some way, sometimes alone, other times with a group against the game world or against other players. A player can for instance choose to enter a "battlefield", where two large groups of players battle each other to determine the winning group. A player can also choose to partake in a "duel", where two players fight against each other to determine a winner. Both "battleground" and "duel" are highly institutionalized actions, where the winner gains medals or "winning points" and there are official competitions for those actions within the game. In both cases, the game designers wrote this kind of "planned violence" in the game structure when they programmed the game. Users are unlikely to refer to those official events as "violence". However, there are also activities that can disturb players' game experience and can leave them feel violated.

Those activities are commonly referred to as "griefing" and according to Foo and Koivisto (2004: 246) are defined as

1. The griefer's act is intentional;

2. It causes other players to enjoy the game less;

3. The griefer enjoys the act.

Based on qualitative interviews with players and developers of virtual worlds, they differentiate between four types of griefing - harassment, power imposition, scamming and greed play. Harassment refers to intentionally causing emotional distress, for instance through hate speech, spatial intrusion or event disruption. Power imposition is almost like harassment, as the attacker also causes distress to his or her victims by exploiting loopholes in the game structure or their own far superior power level. New and inexperienced players are especially prone to this kind of griefing. Foo and Koivisto define scamming as situations, where players do not keep their promises or cheat during transactions. Greed play refers to players who disregard group rules and disadvantage other player, only caring for their own benefits.

Out of the four categories of griefing mentioned by Foo and Koivisto, power imposition could be most interesting for my research question. It could function as a way of showing players their place in society by punishing nonconforming behaviour or new and inexperienced players who do not know the game and its norms. Taylor (2006) comes to similar conclusions from her research in Everquest. She argues that griefing in MMORPGs looks quite different than in other online games where the community aspect is not as strong. The ability of the player community to use social sanctions against griefers makes the difference.

Taylor's main interest is about why so-called "good" players grief or cheat from time to time and less about users who constantly grief. She argues that wanting to cheat the game is a sign of understanding it on a particularly deep level and that the idea of personality types that are especially prone to griefing is the wrong approach since cheating and griefing is not as rare as expected. She further claims to have seen well-respected player "kill-steal" and "teach younger players a lesson" (Taylor, 2006: 51) and that the perception of griefing is deeply contextual. Social norms and rules play an immensely large role. 
To this point, anthropological interest in griefing behaviour has been rather scarce, most publications about this topic come from information and communication technology studies and research has been conducted using interviews and statistics rather than participant observation. Most publications focus on anti-social behaviour and the distress it causes other players, but little has been written about griefing as acts of violence to date. So far, the majority of publications has neglected the questions of what users of virtual worlds experience as violence and which use this violence might have for the virtual world's society. This shows the need for anthropological, qualitative research on the motivations of the inflictors of violence in MMORPGs, as well as on the victim's perspective.

\section{Conclusion.}

While virtual worlds have existed for quite some years, anthropological involvement with them is at its beginning. By conducting several early research projects in emerging virtual worlds, anthropologists managed to get a feeling for this subfield of digital anthropology and have now started to find uses for the knowledge generated. While some anthropologists encourage new methods and approaches like large scale experiments, others prefer to stick to classic ethnographical methods. The field of cyber anthropology is far from being united, as for example the ongoing discussion of terms shows. Despite that, anthropological engagement with virtual worlds promises interesting insights into human society and the growing number of innovative virtual worlds supports this outlook.

Research has indicated that virtual worlds are subject to the same social rules as other societies. Violence therefore also exists in the virtual world, although maybe not in the same way we would expect to find it offline. I argued that institutionalized violent behaviour, like the fights on battlefields, could be used to reaffirm the structures of the virtual world's society, while violence that is not part of the game structure, like griefing, could be seen as disturbance. However, as previous research has indicated, even this kind of violence might serve a social purpose in the game. Further engagement with this promising topic is needed and will be provided with my MAS thesis.

\section{References.}

Bainbridge, W. S. (2007). The Scientific Research Potential of Virtual Worlds. Science, 317(5837), pp. 472-476. http://doi.org/10.1126/science.1146930

Bartle, R. A. (2004). Designing Virtual Worlds. Berkeley: New Riders Publishing. http://doi.org/10.1093/carcin/bgs054

Boellstorff, T. (2008). Coming of Age in Second Life. Princeton, Oxford: Princeton University Press.http://doi.org/https://doi.org/10.1515/9781400874101

Boellstorff, T. (2012). Rethinking Digital Anthropology. In D. Miller \& H. Horst (Eds.), Digital Anthropology, pp. 39-60. London, New York: Berg. 
Boellstorff, T. (2015). Three Real Futures for Virtual Worlds. Journal of Virtual Worlds Research, 8(2), pp. 1-5. JOUR.

Boellstorff, T., Nardi, B., Pearce, C., \& Taylor, T. L. (2012). Ethnography and virtual worlds: A handbook of method. Princeton, Oxford: Princeton University Press. http://doi.org/10.1080/08838159609364336

Budka, P., \& Kremser, M. (2004). CyberAnthropology - Anthropology of CyberCulture. In S. Khittel, B. Plankensteiner, \& M. Six-Hohenbalken (Eds.), Contemporary Issues in Socio-Cultural Anthropology. Perspectives and Research Activities from Austria, pp. 213-226. Vienna: Löcker.

Carter, D. (2005). Denise Carter Living in virtual communities: An ethnography of human relationships in cyberspace. Communication \& Society, 8(2), pp. 148167. http://doi.org/10.1080/13691180500146235

Castronova, E. (2005a). On the research value of large games: Natural experiments in Norrath and Camelot. CESIFO WORKING PAPER.

Castronova, E. (2005b). Synthetic Worlds. the Business and Culture of Online Games. Journal of Chemical Information and Modeling (Vol. 53). Chicago: The University of Chicago Press. http://doi.org/10.1017/CBO9781107415324.004

Castronova, E., \& Falk, M. (2009). Virtual Worlds: Petri Dishes, Rat Mazes, and Supercolliders. Games and Culture, 4, pp. 396-407. http://doi.org/10.1177/1555412009343574

Foo, C. Y., \& Koivisto, E. M. I. (2004). Defining grief play in MMORPGs. In Proceedings of the 2004 ACM SIGCHI International Conference on Advances in computer entertainment technology - ACE '04, pp. 245-250. http://doi.org/10.1145/1067343.1067375

Gluckman, M. (1955). The Peace in the Feud. Past \& Present, 8, pp. 1-14. http://doi.org/doi: 10.1093/past/8.1.1

Hine, C. (2000). Virtual Ethnography. London: SAGE Publications Ltd. http://doi.org/10.4135/9780857020277

Miller, D., \& Horst, H. (2012). Digital Anthropology. (D. Miller \& H. Horst, Eds.). London, New York: Berg.

Nardi, B. (2010). My Life as a Night Elf Priest. University of Michigan Press. http://doi.org/https://doi.org/10.3998/toi.8008655.0001.001

Nardi, B. (2015). Virtuality*. Annual Review of Anthropology, 44(1), pp. 15-31. http://doi.org/10.1146/annurev-anthro-102214-014226 
Pearce, C., \& Artemesia. (2009). Communities of play: Emergent cultures in multiplayer games and virtual worlds. Cambridge, London: The MIT Press. http://doi.org/10.1177/0094306110380384gg

Taylor, T. L. (2006). Play Between Worlds: Exploring Online Game Culture. Cambridge, London: The MIT Press. http://doi.org/10.1353/cj.0.0113

Turkle, S. (1999). Cyberspace and Identity. Contemporary Sociology, 28(6), pp. 643-648. JOUR. http://doi.org/10.2307/2655534

Williams, D. (2010). The Mapping Principle, and a Research Framework for Virtual Worlds. Communication Theory, 20(4), pp. 451-470. JOUR. http://doi.org/10.1111/j.1468-2885.2010.01371.x 